\title{
Evaluating Responsiveness of Raised Serum Ferritin for Treatment in Patients with Chronic Hepatitis C Infection
}

\author{
Hassan A Aziz ${ }^{1}$
}

\begin{abstract}
Background: Hepatitis $C$ virus infection (HCV) is known as a major public health challenge across the world. There is a positive association between iron accumulation in hepatocytes and increased concentration of serum markers, including ferritin and transferrin. The study has aimed to investigate the responsiveness of increased serum ferritin levels among patients suffering HCV infection.

Materials and Methods: The study has recruited 195 patients from the Hamad General Hospital, who were suffering with HCV infection. The clinical characteristics included HCV viral load, biochemical data, and parameters of iron status were evaluated among all the patients. The obtained results were quantitatively analyzed using Microsoft excel 2013.

Results: The results revealed that the correlation between HCV and iron accumulation in hepatocytes is significantly interfered by the anti-viral treatment. The mean value of iron for positive PCR was calculated to be $19.93 \mu \mathrm{mol} / \mathrm{L}$; and for negative $P C R$, the value was estimated to be $24.6 / \mu \mathrm{mol} / \mathrm{L}$ before administration of drug. The iron level was $62.77 \mu \mathrm{mol} / \mathrm{L}$ among the patients with positive $P C R$, which is within normal range. The decrease in level of ferritin represents negative results after the drug administration. Increased levels of ALT were observed among 37.62 percent of the patients.

Conclusions: The patients, suffering from chronic HCV, possess significant association with serum iron levels. Keywords: Drug; Ferritin Levels; Hepatitis C Virus Infection; Iron Load; Liver Cells; Serum

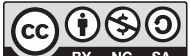

DOI: https://doi.org/l0.3329/jom.v2lil.44095

Copyright: (C) 2020 Aziz HA. This is an open access article published under the Creative Commons Attribution-NonCommercial-NoDerivatives 4.0 International License, which permits use, distribution and reproduction in any medium, provided the original work is properly cited, is not changed in any way and it is not used for commercial purposes.
\end{abstract}

Received: 22 November, 2018;

Accepted: 15 February, 2019

\section{Introduction:}

Hepatitis $\mathrm{C}$ virus infection (HCV) is considered as a major public health problem globally. The prevalence of $\mathrm{HCV}$ is estimated to be $3 \%$ worldwide; out of which, approximately 170 billion people are affected with the hepatitis $\mathrm{C}$ antibody. ${ }^{1,2}$ Around $20 \%$ of chronic hepatitis C (CHC) cases progressed to cirrhosis that is a life-threatening hepatic condition. ${ }^{2}$ Other risk factors associated with $\mathrm{CHC}$ are decompensated liver disease and hepato-cellular carcinoma, which ultimately requires liver transplantation. Different viral

1. Associate Dean for Academic, Faculty and Student Affairs. Professor, Department of Clinical Laboratory Sciences, College of Health Professions, University of Tennessee Health Science Center, 930 Madison Avenue, Suite 632A, Memphis, TN 38163, USA.

Corresponding author: Dr. Hassan A. Aziz, Associate Dean for Academic, Faculty and Student Affairs. Professor, Department of Clinical Laboratory Sciences, College of Health Professions, University of Tennessee Health Science Center, 930 Madison Avenue, Suite 632A, Memphis, TN 38163, USA. Contact: 901-448-3164, email: hassan.aziz.mls@gmail.com. factors (such as genotype and baseline viral load), comorbidities, and genetic background of the host characterize the outcomes of HCV infection.

Hepatocytes are responsible for storing approximately $1 / 3^{\text {rd }}$ of total body's iron; therefore, liver has been known as a major organ for iron storage. ${ }^{3}$ The main storage protein ferritin and the major transporting protein transferrin are synthesized in the liver; therefore, liver plays a significant role in the iron metabolism. The positive association between increased concentration of serum iron markers (such as iron, ferritin, and transferrin) and accumulation of iron in liver among patients, suffering from $\mathrm{CHC}$, have been reported by few studies. ${ }^{2,4,5}$ However, the diagnosis of cirrhosis in $\mathrm{CHC}$ is significant because liver fibrosis at stage III and IV is mostly observed. Therefore, there is a higher risk of liver decompensation among the patients, suffering from advanced liver fibrosis. ${ }^{1}$

\section{Problem Statement}

Iron is an important element for the human body. However, complex association between viral infections and iron 
homeostasis is a critical issue. The prevalence of iron overload in liver, its interaction with severity of disease, and its impact on the response to the treatment are not clear. Some of the patients suffering HCV achieve sustained elimination from HCV when they are given advanced treatment therapies. The results of previously published literature have indicated the association between $\mathrm{CHC}$ and accumulation of iron in liver cells, which significantly interferes with the anti-viral treatment. Similarly, a study revealed that severe iron overload is not significantly associated with $\mathrm{HCV}$ infected patients. ${ }^{6}$ Whereas, the concentration of hepatic iron is decreased among majority of the patients, affected with HCV infection. ${ }^{7}$ Therefore, this study would help in the evaluation of the responsiveness of increased ferritin serum levels for the treatment of patients, suffering $\mathrm{CHC}$ infection.

\section{Aim of the Study}

The study has mainly focused on the responsiveness of raised serum ferritin levels against the treatment of the patients with $\mathrm{CHC}$ infection.

\section{Materials and Methods:}

The study has incorporated quantitative analysis and recruited patients, suffering with $\mathrm{CHC}$ infection and positive anti-HCV. The informed consent of the patients was received. The investigation was conducted in Qatar University after the results were obtained from Hamad General Hospital. The data was obtained over a period of five years from January 2010 till March 2015. The study has taken ethical approval from Medical Research Center (MRC) of Hamad Medical Corporation (HMC). Similarly, the statement of ethical approval acknowledgment was obtained from the Institutional Review Board of Qatar University (QU-IRB) on March $10^{\text {th }} 2016$. One hundred and ninety-five patients $(\mathrm{N}=$ $195)$ with HCV were investigated as participants. All of the participants were positive for anti-HCV antibodies, detected by chemiluminescent micro-particle immunoassay (CMIA) and confirmed by real-time PCR for RNA of the virus. The clinical characteristics, HCV viral load, biochemical data, and parameters of iron status were evaluated among all the patients. The hepatic iron concentration (HIC) was determined and compared with age, gender, risk factor of transmission, viral load, and alanine amino-transferase (ALT). ALT was measured through the automatic analyzer (Roche Modular P chemistry analyzer). All the recruited patients received same treatments that are the interferon treatment to gather accurate results. Interferon treatment is considered as a common viral intervention. Paired samples t-test was used to calculate the p-value and correlation co-efficient. Microsoft Excel 2013 was used to analyze the prevalence of
HCV infection among subjects of different sexes, and nationality.

\section{Results:}

The results have indicated association between $\mathrm{CHC}$ and accumulation of iron in liver cells, which significantly interferes with the anti-viral treatment. The anti-viral treatment is likely to cure and reduce the risk of developing liver disease among the HCV infected patients. Majority of the patients still had undetected viral loads after getting interferon treatment. The possibility of eliminating HCV with anti-viral treatment increased the removal of iron by phlebotomy. The prevalence of $\mathrm{HCV}$ among 195 patients depicted that $27 \%$ were females and $73 \%$ were males. The results showed that the mean value of iron for positive PCR before administration of drug was calculated to be $19.93 \mu \mathrm{mol} / \mathrm{L}$; and for negative PCR, the value was estimated to be $24.61 \mu \mathrm{mol} / \mathrm{L}$ (Figure 1). Both these ranges were under normal range that is between $9-31.3 \mu \mathrm{mol} / \mathrm{L}$. Among the patients with positive PCR, the iron level was $62.77 \mu \mathrm{mol} / \mathrm{L}$, which is within normal range. However, the patients with positive PCR had iron level of $37.23 \mu \mathrm{mol} / \mathrm{L}$, which is not within the normal range.

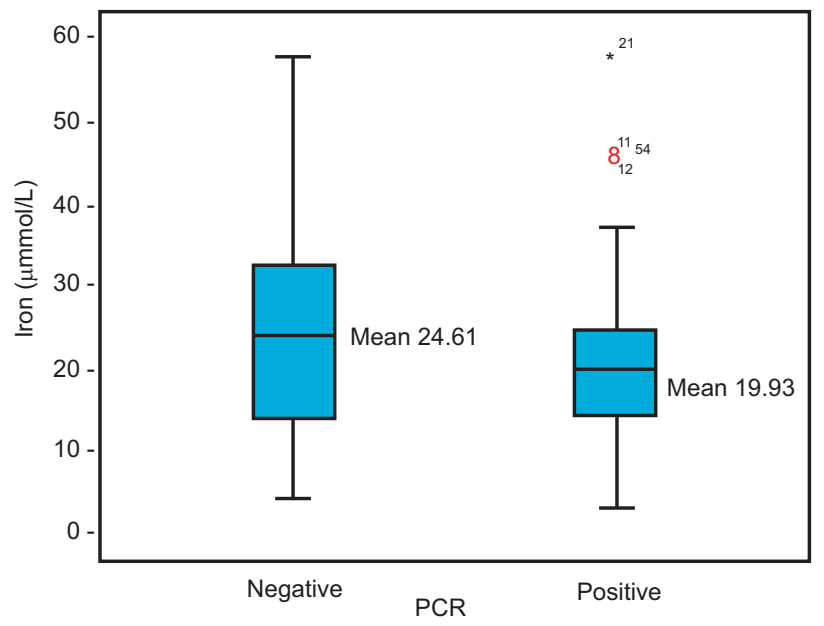

Figure 1: Effect of HCV on iron $(\mu \mathrm{mol} / \mathrm{L})$ in positive and negative PCR patients.

The mean value of ferritin for negative PCR $(671.83 \mu \mathrm{mol} / \mathrm{L})$ and positive $\mathrm{PCR}(911.61 \mu \mathrm{mol} / \mathrm{L})$ were estimated to be above normal range that is between $221-641.35 \mu \mathrm{mol} / \mathrm{L}$ (Figure 2). The decrease in ferritin level depicted negative results after the drug administration. The results further showed that $30.61 \%$ of the participants had ferritin level above normal range and $69.38 \%$ individuals had ferritin level within normal range, which represented positive PCR. Table 1 has shown negative PCR as follow-up. This is because the results from the positive PCR are from the time of initial diagnosis, and the negative results are followed after the treatment. 


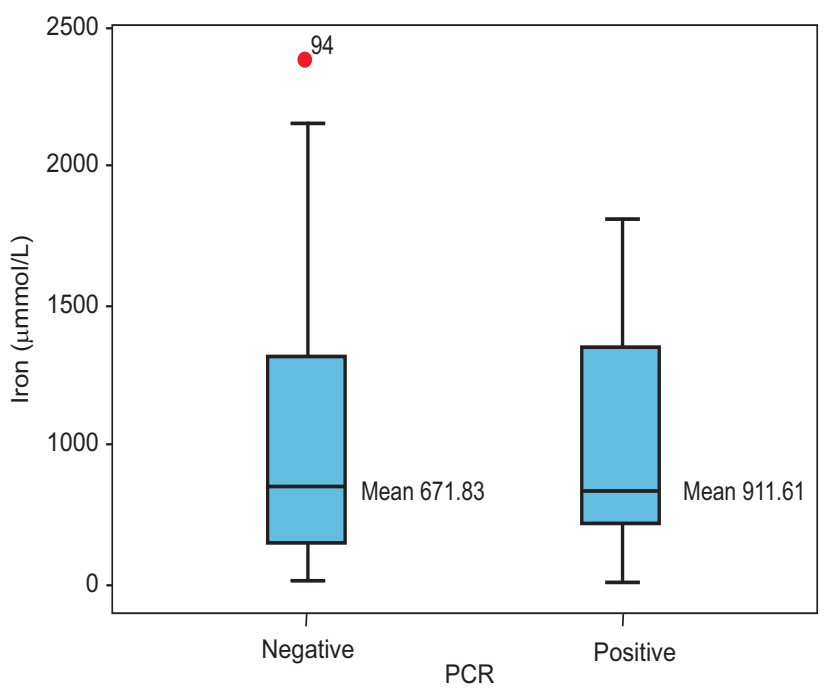

Figure 2: Effect of HCV on Ferritin ( $\mathrm{Hmol} / \mathrm{L})$ in positive and negative PCR patients.

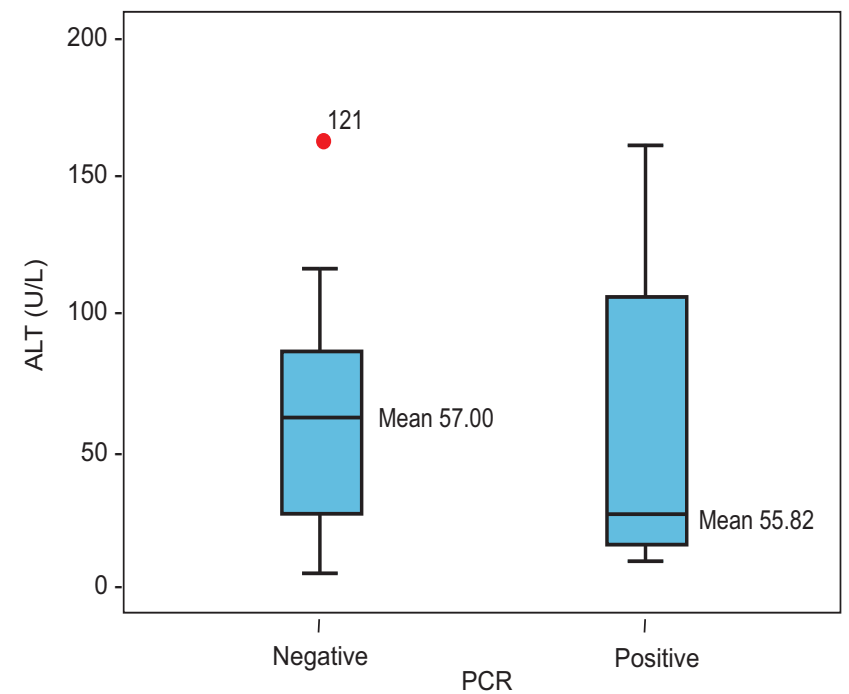

Figure 3: Effect of HCV on ALT (imol/L) in positive and negative PCR patients

Table I: Summary of p-values \& $r$-values for Iron, Ferritin, and ALT after the treatment

\begin{tabular}{llcccc}
\hline Parameters & PCR & Mean & SD & r-value & p-value \\
\hline Iron $(\mu \mathrm{mol} / \mathrm{L})$ & (Initially/ Positive PCR) & 19.93 & 9.73 & 0.541 & 0.001 \\
& (Follow up/ Negative PCR) & 24.61 & 12.97 & & \\
Ferritin $(\mu \mathrm{mol} / \mathrm{L})$ & (Intially/ Positive PCR) & 911.61 & 630.18 & 0.450 & 0.182 \\
& (Follow up / Negative PCR) & 671.83 & 523.81 & & \\
ALT $(\mathrm{imml} / \mathrm{L})$ & (Initially/ Positive PCR) & 55.82 & 50.94 & 0.362 & 0.812 \\
& (Follow up/ Negative PCR) & 57.00 & 33.32 & & \\
\hline
\end{tabular}

$\mathrm{N}=195$

The ALT levels among patients were observed to increase to $57 \mu \mathrm{mol} / \mathrm{L}$ (positive PCR) from $55.82 \mathrm{imol} / \mathrm{L}$ (negative PCR) after receiving treatment (Figure 3). However, the reference range is between 6-56 imol/L. Considering the ALT levels, $62.37 \%$ of the patients were within normal range with positive PCR; moreover, increased levels of ALT above normal range were observed in $37.62 \%$ of patients. The ALT levels in individuals with negative PCR were half among $48.04 \%$ of the patients, which is within the normal range. Table 1 shows the correlation between liver enzymes and iron markers with initial HCV load and after its treatment.

\section{Discussion:}

The findings have indicated that the prevalence of $\mathrm{HCV}$ infection is higher among male patients as compared to female patients. Majority of the patients, who received interferon treatment as a common viral intervention, were not detected with viral loads. World Health Organization (WHO) has primarily described complete guidelines for the patients, suffering from $\mathrm{CHC}^{8}{ }^{\mathrm{T}}$ The mortal and morbid cases have been estimated to be increased at a higher scale across the globe related to hepatitis $\mathrm{C}$ virus (HCV) infection. It has been identified that approximately 700,000 individuals generally faced mortal complications annually because of HCV-related symptoms, which clinically involved cirrhosis and hepatocellular carcinoma (HCC). ${ }^{9}$

World Health Organization further identified that the cure of $\mathrm{HCV}$ infection is possible through antiviral treatment; however, most of the infected individuals are mostly unaware about their infection due to the asymptomatic nature of the disease. World Health Organization (WHO) also issued the initial guidelines in respect to the screening, care, and treatment of individuals, having hepatitis $\mathrm{C}$ infection during the year 2014. ${ }^{9}$ Several medicines have been developed by different organizations and professionals for the treatment of HCV infection. Among those therapeutic interventions, ledipasvir, daclatasvir, or combination of paritaprevir, ombitasvir, and dasabuvir have been added in the WHO Model List of Essential Medicines. Such medications have 
transformed HCV treatment, which has enabled the usage of regimens.

Accordingly, such guidelines from World Health Organization has aimed to provide various recommendations, based on recent and past evidence, for developing the therapeutic interventions of hepatitis $\mathrm{C}$ infection. ${ }^{9}$ The guidelines have mostly provided oral combinations of new medications that are generally known as direct-acting antivirals (DAAs). Guidelines have also shown certain recommendations related to the preferred regimens, which were based on patients' genotype and clinical history. Similarly, the key audience of these guidelines is policy-makers among the low income and middle-income countries, which has formulated specified treatment guidelines. ${ }^{9}$ Therefore, it is said that the guidelines are in accordance with the higher therapeutic standards for all the countries, including lower to higher income countries.

Ruhl \& Everhart ${ }^{8}$ have described that non-alcohol-induced fatty liver (NAFL) usually encompasses the risk of liver injury, which can be ranged from benign accumulation of fat among hepatocytes to complex non-alcohol-induced steatohepatitis, which can be progressed towards liver failure and cirrhosis among patients. The study has concluded that the risk of liver injury is directly associated with the elevated level of iron and decreased antioxidants, particularly carotenoids. Thorburn, et al. ${ }^{9}$ has identified different factors, which were proposed for the observed variation. The factors have mainly included male gender, HCV genotype $1 \mathrm{~b}$, older age at acquisition of infection, and excess alcohol consumption. Moreover, the study has also mentioned that the role of iron is significantly important in chronic HCV infection. ${ }^{10}$ It is recognized that iron overload in hepatic cells has promoted hepatic ûbrosis. Moreover, serum iron is observed to be frequently increased among patients, having chronic hepatitis $\mathrm{C}$. It has been further evaluated that increased rates of liver ûbrosis has been reported among $\mathrm{HCV}$ infected patients, having stainable iron as compared to the controls, having no detectable hepatic iron. ${ }^{10}$

A process, in which accumulation of iron occurs, has not been established among patients, suffering from HCV. However, the results of iron release from damaged hepatocytes plays a major role in identifying relative outcomes. Based on the advanced investigation, it is discovered that the mutations in HFE gene have accounted for the increased cases of hereditary hemochromatosis. Moreover, increased interest has been shown towards identifying the development and progression of other liver diseases. At the same time, experiments have shown that two recessively inherited missense mutations of HFE gene has been resulted in the amino acid substitutions at position
282 (cysteine to tyrosine, Cys282Tyr) along with the position of 63 (histidine to aspartic acid, His63Asp). Therefore, around $90 \%$ of the patients from UK with hereditary hemochromatosis were homozygous. 10

There is a significant association between liver enzymes and viral load. A similar study revealed that severe iron overload is not significantly associated with $\mathrm{HCV}$ infected patients. ${ }^{11}$ Whereas, the concentration of hepatic iron is decreased among majority of the patients infected with HCV. ${ }^{12}$ There is a significant correlation between $p$-value of serum iron with viral load, reflecting the development of viral intervention using interferon. A study conducted by Shan et al. ${ }^{13}$ has revealed strong association between HCV and level of serum iron.

The undetected viral load is associated with the fluctuation in ferritin levels among the patients before and after receiving treatment. Although, ferritin levels were increased before treatment; but after intervention, the ferritin levels were likely to decrease. It shows that there is a strong association between ferritin and HCV. Considering the ALT levels, high borderline results were observed before receiving treatment; whereas, after treatment, slight increase was observed in the ferritin levels. HCV load and liver enzyme were not significantly correlated, but a study conducted by Zechini et al. ${ }^{14}$ indicated strong association between ALT levels and hepatic damage.

The liver enzymes were likely to decrease after treatment, if they are not back to their normal range. In the current study, the parameters including iron, ferritin, and ALT were increased in majority of the $\mathrm{HCV}$ patients, after receiving treatment because the liver might not have recovered. HCV is likely to cause chronic infection because of decreased immunity due to rapid mutations and escaping of virus from the immune system. ${ }^{15}$ Therefore, the human body requires considerable time to recover from the infection. There are many other factors that influence the results of the iron and ferritin; including inflammations, chronic illnesses, and certain medications. The results are also affected by increased intake of milk, running for long distances, and frequent donation of blood. Previously conducted studies have also revealed that incidence of HCV infection is increased among the male patients as compared to the female individuals. ${ }^{16,17}$

A study revealed that majority of $\mathrm{HCV}$ infected patients had normal range of iron makers in blood serum. However, early markers representing severity of liver disease include; increased serum levels of ferritin, transferrin, and iron. ${ }^{16}$ The increased levels of ferritin, transferrin, and iron initiated necroin-inflammatory hepatic response, which cause excessive release of ferritin and iron from the liver cells 
(hepatocytes). Moreover, this process is sustained by increased serum ALT levels. Oxidative stress followed by $\mathrm{HCV}$ infection resulted in liver damage, which increased the risk of apoptosis or necrosis of the hepatocytes, fibrogenesis, and activated hepatic stellate cells. ${ }^{16,17}$

A slight increase in the iron levels if combined with hepatotoxic factors like chronic viral hepatitis may cause severe damaging effects. The serum iron levels and transferrin are considered as independent predictors of severe necroinflammatory activity. The iron alterations are linked with mutations occurring in different iron-metabolism related genes. A study conducted by Cho et al. ${ }^{18}$ stated that the iron metabolism markers and HCV viral load are not significantly correlated. There is an independent association between development of advanced liver fibrosis and transferrin and ferritin levels. It serves as predictive markers to diagnose the patients, suffering from $\mathrm{HCV}$.

The study has not included severity of liver disease among the affected patients and it is just concerned with the evaluation of the responsiveness of raised serum ferritin for treating patients suffering hepatitis C. Moreover, the study has not provided specific details about the virological and histological features that are concerned with the condition of HCV. Other limitations of the study include missing information about medical and health history of the patients and multiple factors (controllable and uncontrollable), which have not inferred the testing results.

\section{Conclusions:}

The study has evaluated HCV positive patients, and reevaluated them after giving effective interferon treatment. The increased levels of ferritin and iron were significantly associated with the condition, leading to advanced liver fibrosis. There is no significant difference in the iron markers among the patients with high or low HCV infection. The severity of disease is easily determined through the assessment of transferrin and ferritin levels, which are related to the development of necro-inflammatory activity and liver fibrosis. The common finding associated with $\mathrm{HCV}$ was iron overload, which plays a significant role in its pathophysiology. However, serum levels of transferrin and ferritin were not considered as good indicators to detect hepatic iron content. There is no evidence for the impact of hepatic iron on progression of hepatic disease, leading to cirrhosis and fibrosis. The patients are likely to develop liver damage due to chronic $\mathrm{HCV}$ within the hepatocytes. Ferritin levels are usually found higher among patients suffering chronic $\mathrm{HCV}$; and it can be used for the diagnosis of inflammation grades and liver fibrosis.

\section{Acknowledgement:}

The author is very thankful to all the associated personnel in any reference that contributed in/for the purpose of this research.

\section{Conflict of Interest: None.}

\section{References:}

1. Veldt BJ, Heathcote EJ, Wedemeyer H, Reichen J, Hofmann WP, Zeuzem S et al. Sustained virologic response and clinical outcomes in patients with chronic hepatitis $\mathrm{C}$ and advanced fibrosis. Ann Intern Med 2007;147:677-84. http://dx.doi.org/ 10.1016/s0084-3873(08)79059-x

2. Vagu C, Sultana C, Ruta S. Serum iron markers in patients with chronic hepatitis $\mathrm{C}$ infection. Hepatitis monthly 2013;13. http://dx.doi.org/10.5812/hepatmon.13136

3. Itoh Y. Pathogenic role of iron deposition in reticuloendothelial cells during the development of chronic hepatitis C. International journal of hepatology 2013;2013. http:// dx.doi.org/10.1155/2013/686420

4. Bonkovsky HL. Iron as a comorbid factor in chronic viral hepatitis. The American journal of gastroenterology 2002;97:1. http://dx.doi.org/10.1016/s0002-9270(01)039521

5. Metwally MA, Zein CO, Zein NN. Clinical significance of hepatic iron deposition and serum iron values in patients with chronic hepatitis $\mathrm{C}$ infection. The American journal of gastroenterology 2004;99:286-91. http://dx.doi.org/10.1111/ j.1572-0241.2004.04049.x

6. World Health Organization. Guidelines for the Screening, Care and Treatment of Persons with Chronic Hepatitis C Infection. 2016.

7. Goossens N, Clement S, Negro F. Handbook of Hepatitis C. Adis; 2016.

8. Ruhl CE, Everhart JE. Relation of elevated serum alanine aminotransferase activity with iron and antioxidant levels in the United States. Gastroenterology 2003;124:1821-9. http:/ /dx.doi.org/10.1016/S0016-5085(03)00395-0

9. Thorburn D, Curry G, Spooner R, Spence E, Oien K, Halls D, Fox R, McCruden EA, MacSween RN, Mills PR. The role of iron and haemochromatosis gene mutations in the progression of liver disease in chronic hepatitis C. Gut 2002;50:248-52. http://dx.doi.org/10.1136/gut.50.2.248

10. Pereira PD, Uehara SN, Emori CT, Lanzoni VP, Silva AE, Ferraz ML. Chronic hepatitis C: hepatic iron content does not correlate with response to antiviral therapy. Revista do Instituto de Medicina Tropical de Sao Paulo 2009;51:331-6. http://dx.doi.org/10.1590/s0036-46652009000600004

11. Guyader D, Thirouard AS, Erdtmann L, Rakba N, Jacquelinet S, Danielou H, Perrin M, Jouanolle AM, Brissot P, Deugnier 
Y. Liver iron is a surrogate marker of severe fibrosis in chronic hepatitis C. J Hepatol 2007;46:587-95. http://dx.doi.org/ 10.1016/j.jhep.2006.09.021

12. Noreldin AKA, Mohamed AS, Abdelaziz AH, Ali GAM. Correlation between Liver Function Tests and Polymerase Chain Reaction in Chronic Hepatitis C Patients. Journal of Hepatology and Gastrointestinal Disorders 2015;1:110. http:/ /dx.doi.org/10.4172/jhgd.1000110

13. Shan Y, Lambrecht RW, Bonkovsky HL. Association of hepatitis $\mathrm{C}$ virus infection with serum iron status: analysis of data from the third National Health and Nutrition Examination Survey. Clin Infect Dis 2005;40:834-41. http:/ /dx.doi.org/1058-4838/2005/4006-0010\$15.00

14. Zechini B, Pasquazzi C, Aceti A. Correlation of serum aminotransferases with HCV RNA levels and histological findings in patients with chronic hepatitis $\mathrm{C}$ : the role of serum aspartate transaminase in the evaluation of disease progression. European journal of gastroenterology \& hepatology 2004;16:891-6. http://dx.doi.org/10.1097/ 00042737-200409000-00013

15. Farci P, Shimoda A, Coiana A, Diaz G, Peddis G, Melpolder JC, Strazzera A, Chien DY, Munoz SJ, Balestrieri A, Purcell $\mathrm{RH}$. The outcome of acute hepatitis $\mathrm{C}$ predicted by the evolution of the viral quasispecies. Science 2000;288:33944. http://dx.doi.org/10.1126/science.288.5464.339

16. Fujita N, Sugimoto R, Ma N, Tanaka H, Iwasa M, Kobayashi Y, Kawanishi S, Watanabe S, Kaito M, Takei Y. Comparison of hepatic oxidative DNA damage in patients with chronic hepatitis B and C. J Viral Hepat 2008;15:498-507.

17. Ramm GA, Ruddell RG. Hepatotoxicity of iron overload: mechanisms of iron-induced hepatic fibrogenesis. InSeminars in liver disease 2005 Nov (Vol. 25, No. 04, pp. 433-449). Copyright $(\mathcal{} 2005$ by Thieme Medical Publishers, Inc., 333 Seventh Avenue, New York, NY 10001, USA.

18. Cho H, Lee HC, Jang SK, Kim YK. Iron increases translation initiation directed by internal ribosome entry site of hepatitis C virus. Virus Genes 2008;37:154-60. 